Article

\title{
Scale and Landscape Features Matter for Understanding Waterbird Habitat Selection
}

\author{
Jinya Li ${ }^{1,+}\left(\mathbb{D}\right.$, Yang Zhang ${ }^{1,2}$, Lina Zhao ${ }^{2,3}$, Wanquan Deng ${ }^{4}$, Fawen Qian ${ }^{5,+}$ and Keming Ma ${ }^{1,2, *}$ \\ 1 State Key Laboratory of Urban and Regional Ecology, Research Center for Eco-Environmental Sciences, \\ Chinese Academy of Sciences, Beijing 100085, China; jyli@rcees.ac.cn (J.L.); \\ zhangyang182@mails.ucas.ac.cn (Y.Z.) \\ 2 University of Chinese Academy of Sciences, Beijing 100049, China; zhaoln@ibcas.ac.cn \\ 3 State Key Laboratory of Systematic and Evolutionary Botany, Institute of Botany, \\ Chinese Academy of Sciences, Beijing 100093, China \\ 4 The College of Forestry, Beijing Forestry University, Beijing 100083, China; dengwanquan@gxhky.org \\ 5 Key Laboratory of Biodiversity Conservation of National Forestry and Grassland Administration, \\ Research Institute of Forest Ecology, Environment and Protection, Chinese Academy of Forestry, \\ Beijing 100091, China; cranenw@caf.ac.cn \\ * Correspondence: mkm@rcees.ac.cn; Tel.: +86-010-62849104 \\ + Jinya Li and Fawen Qian contributed equally to this work.
}

Citation: Li, J.; Zhang, Y.; Zhao, L.; Deng, W.; Qian, F.; Ma, K. Scale and Landscape Features Matter for Understanding Waterbird Habitat Selection. Remote Sens. 2021, 13, 4397. https://doi.org/10.3390/rs13214397

Academic Editors: Li Wen and Guangchun Lei

Received: 2 October 2021

Accepted: 29 October 2021

Published: 31 October 2021

Publisher's Note: MDPI stays neutral with regard to jurisdictional claims in published maps and institutional affiliations.

Copyright: (c) 2021 by the authors. Licensee MDPI, Basel, Switzerland. This article is an open access article distributed under the terms and conditions of the Creative Commons Attribution (CC BY) license (https:// creativecommons.org/licenses/by/ $4.0 /)$.

\begin{abstract}
Clarifying species-environment relationships is crucial for the development of efficient conservation and restoration strategies. However, this work is often complicated by a lack of detailed information on species distribution and habitat features and tends to ignore the impact of scale and landscape features. Here, we tracked 11 Oriental White Storks (Ciconia boyciana) with GPS loggers during their wintering period at Poyang Lake and divided the tracking data into two parts (foraging and roosting states) according to the distribution of activity over the course of a day. Then, a threestep multiscale and multistate approach was employed to model habitat selection characteristics: (1) first, we minimized the search range of the scale for these two states based on daily movement characteristics; (2) second, we identified the optimized scale of each candidate variable; and (3) third, we fit a multiscale, multivariable habitat selection model in relation to natural features, human disturbance and especially landscape composition and configuration. Our findings reveal that habitat selection of the storks varied with spatial scale and that these scaling relationships were not consistent across different habitat requirements (foraging or roosting) and environmental features. Landscape configuration was a more powerful predictor for storks' foraging habitat selection, while roosting was more sensitive to landscape composition. Incorporating high-precision spatiotemporal satellite tracking data and landscape features derived from satellite images from the same periods into a multiscale habitat selection model can greatly improve the understanding of species-environmental relationships and guide efficient recovery planning and legislation.
\end{abstract}

Keywords: species distribution models; satellite tracking; multiscale model; landscape composition and configuration; variance partitioning analysis

\section{Introduction}

Identifying habitat features for crucial life-history phases is more critical than ever since habitat loss and degradation are the primary drivers of species imperilment and extinction, especially when habitats are exposed to disturbance from climatic and anthropogenic modification [1,2]. Many species rely on different resources throughout the day, across seasons, or during different life cycle stages [3]. Species distribution models (SDMs), which provide information on the relationships between species distributions and the surrounding environments, is among the most important first steps in guiding imperiled species recovery planning and legislation [4-7]. However, this work is often complicated by the lack of detailed information on species distribution and habitat features [8]. 
Species distribution data derived from traditional field investigations are prone to identification errors and geographic biases [9]. Additionally, field investigations are time consuming, costly, and frequently biased by accessibility, which constrains the acquisition of sufficient occurrence data required for the study of habitat selection. This easily leads to cognitive bias. Satellite tracking technology provides an opportunity to continuously record precise locations of species throughout the day or during a specific period of their life stage, which can be of great benefit for in-depth research on habitat selection strategies and movement patterns $[10,11]$. Such fine-tuning of occurrences makes functionally distinct SDMs a reality. Multiple partitioned SDMs may more appropriately account for changing species-environment relationships [3], as the environmental predictors and their importance may differ with changing behaviors [12-14], seasons [15], or life stages [16].

Furthermore, species-environment relationships can differ in terms of both magnitude and direction when they are measured at different scales [17,18]. We do not usually know the optimal scale for a given environmental variable and the biological response it causes [7]. It is not surprising that the relative importance of environmental variables varies with scale [19]. Many traditional SDM studies typically rely on empirical judgement or hypotheses to identify the most meaningful scale [20]. However, ignoring the procedure for identifying "which scales matter", the cumulative effects across multiple scales may reduce the predictive power of SDM and increase misinterpretations of species-environment relationships $[21,22]$. The dependence of ecological patterns and processes on drivers acting across multiple scales has always aroused great concern in landscape ecology $[20,23,24]$. An increasing number of studies have emphasized the important role of landscape ecology in shaping species-environment relationships $[25,26]$. However, although the importance of multiscale analyses has been recognized in the study of species-environment relationships, few published habitat ecology papers address this issue [22]. There remains a significant gap in the application of landscape ecology theories to wildlife ecology research [27-29].

Oriental White Stork, the population of which has rapidly declined over the last several decades and was estimated at $<2500$ individuals worldwide, is listed as an "endangered" species by the IUCN [30]. In the face of the increasing impact of human disturbance and climate change, the conservation of species and their habitats has become increasingly urgent. Against this background, clarifying species-environment relationship is becoming more significant and necessary. We hypothesized that the habitat selection of the storks would vary with spatial scale. We further hypothesized that these scaling relationships would not necessarily be consistent among different habitat requirements (foraging or roosting) and environmental features. Therefore, in this study, our goals were twofold: (1) to evaluate the influence of scale across a set of environmental predictors in habitat selection and identify the scale at which each of these variables is most important and (2) to identify the multiscale species-environment relationship and relative importance of different environmental variables at their optimal scale for different habitat requirements. These results can help generate explicit landscape-scale management recommendations for stork conservation planning that may enhance the persistence and potential expansion of the last remnants of this species' populations.

\section{Materials and Methods}

\subsection{Study Area}

As the largest freshwater lake in China, Poyang Lake $\left(28^{\circ} 22^{\prime}-29^{\circ} 45^{\prime} \mathrm{N}, 115^{\circ} 47^{\prime}-116^{\circ} 45^{\prime} \mathrm{E}\right.$, Figure 1) is located on the southern bank of the Yangtze River, China. The combined effects of inflows from five tributary rivers (the Ganjiang, Xinjiang, Fu, Rao, and Xiu Rivers) and interchanges with the Yangtze River result in considerable seasonal fluctuations in water levels and landscapes. In the wet season (June to September), Poyang Lake presents a lake landscape with a water area exceeding $4000 \mathrm{~km}^{2}$, while it presents a riverine wetland landscape with a water area less than $1000 \mathrm{~km}^{2}$ in the dry season (November to March) [31]. The sharp decline in the water level, together with the gentle topography, results in the emergence of a rich and diverse wetland landscape, making Poyang Lake 
an important wintering ground along the East Asian-Australasian Flyway. It is listed on Ramsar's List among the first seven wetlands with international importance (https: / / rsis.ramsar.org/ris/2310, accessed on 3 August 2020) and is also included in the Global Living Lakes Network (https:/ / www.globalnature.org/livinglakes, accessed on 3 August 2020) as the only wetland in China [32]. More than 400,000 waterbirds winter in Poyang Lake each year, including at least 14 endangered species on the IUCN Red List, such as the critically endangered Siberian Crane (Leucogeranus leucogeranus), the endangered Oriental White Stork and the vulnerable Swan Goose (Anser cygnoides), which account for $98 \%, 75 \%$ and $85 \%$ of each species' global population, respectively [33]. Poyang Lake plays an important and irreplaceable role in biodiversity conservation and regional ecological security.

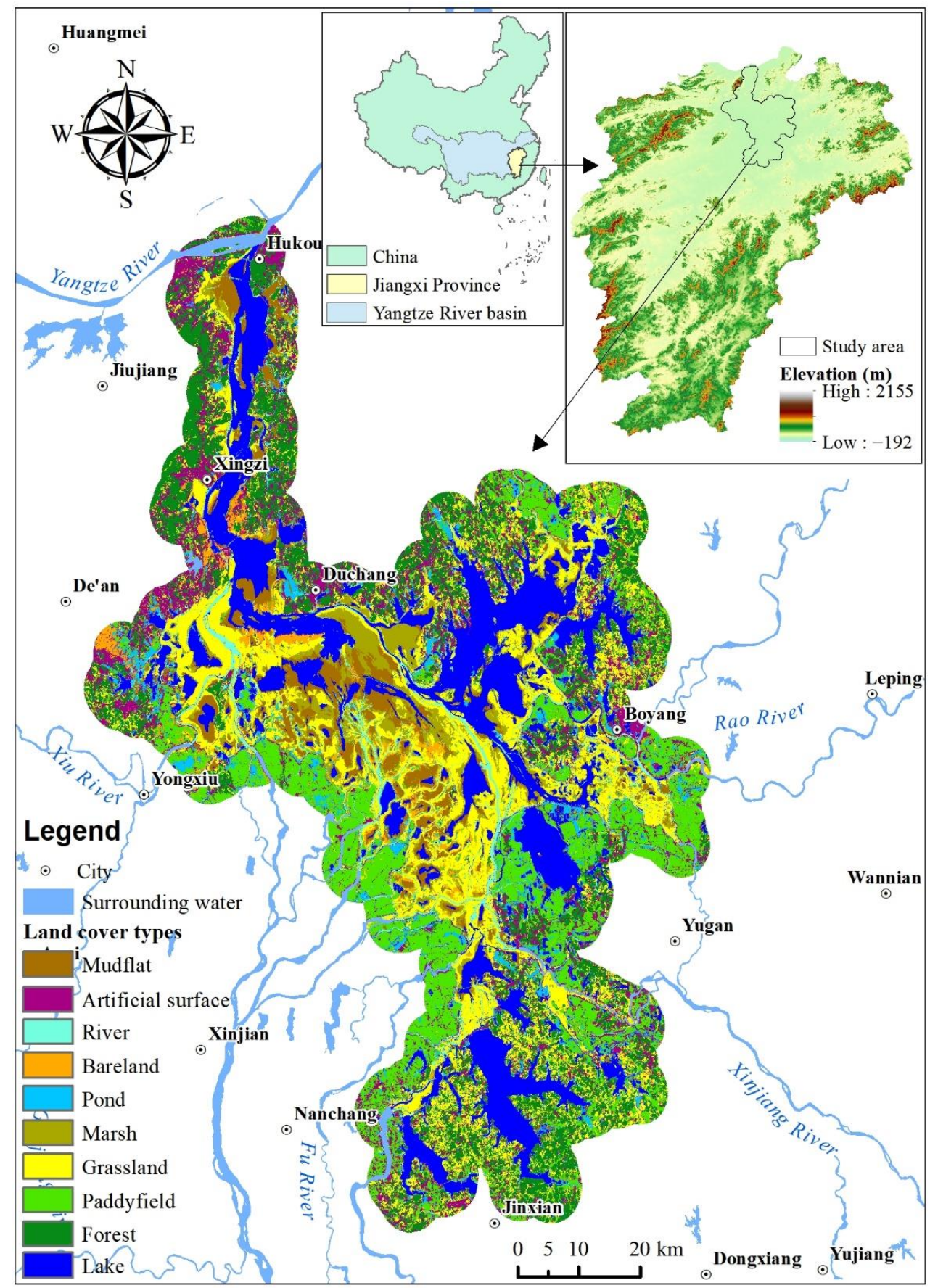

Figure 1. Location of the study area. 


\subsection{Satellite Tracking Data}

During March 2018, 11 Oriental White Storks were captured at their wintering site in Poyang Lake on the Yangtze River Floodplain, Jiangxi Province, China, and equipped with solar-powered data-logging GPS-GSM (Global Positioning System-Global System for Mobile Communications) tracking devices (constructed by Hunan Global Messenger Technology Co. Ltd., Hunan, China). These devices, with a weight that did not exceed 5\% of the storks' body mass, were programmed to record data every $1 \mathrm{~h}$. Of the collected data, latitude, longitude, speed, precision, date and time were used in this study.

We used the locations covering the period from 3 days after the storks reached Poyang Lake to 3 days before they left Poyang Lake as the wintering data [10,34]. Despite missing GPS records due to satellite acquisition failure or low battery level, 16,450 records with positioning accuracy $\leq 30 \mathrm{~m}$ (accuracy grades $\mathrm{A}( \pm 5 \mathrm{~m}), \mathrm{B}( \pm 10 \mathrm{~m})$, and $\mathrm{C}( \pm 20 \mathrm{~m}))$ were collected for the 11 storks.

In designing a multistate SDM, occurrences are separated into different parts according to time or behavior, which are hereafter referred to as states [3]. During wintering at Poyang Lake, the state of the storks can mainly be divided into two types: foraging and roosting. Before identifying the state, the travel distance and time between locations were calculated. The hourly distribution of the travel distance over the course of a day was used to assess the birds' starting and ending activity times for a day (Figure 2). As waterbirds mostly forage during the daytime, points recorded during the starting and ending activity times in the daytime were labelled as a foraging state; otherwise, they were labelled as a roosting state. If there are no missing records, there should be 15 foraging records and 9 roosting records for a given day. This formed the original point sets, which we named Foraging $\mathrm{A}$ (10,293 locations) and Roosting A (6156 locations). These two data sets were then processed in the following two ways:

(1) Identify the research scale

If a bird had fewer than 12 foraging points in a day (out of a total of 15, i.e., less than $80 \%$ of the maximum number), the foraging data for that day were removed to avoid underestimating its foraging range. Similarly, cases with fewer than 8 roosting points a day (out of a total of 9) were deleted. This approach produced the point sets Foraging $B$ (7665 locations) and Roosting B (4731 locations). Then, the 95\% kernel isopleths based on Foraging B and Roosting B were estimated to represent areas used in the foraging and roosting states $[14,28,35]$. The mean radius of these isopleths was calculated to guide the following scale analysis [7]: foraging radius $4.60 \mathrm{~km}(95 \% \mathrm{CI}=4.10 \sim 5.10 \mathrm{~km})$ and roosting radius $0.66 \mathrm{~km}(95 \% \mathrm{CI}=0.55 \sim 0.78 \mathrm{~km})$. Finally, gradient scales of $1.5 \mathrm{~km}, 3 \mathrm{~km}, 5 \mathrm{~km}$, $8 \mathrm{~km}$, and $10 \mathrm{~km}$ for the foraging state and $0.1 \mathrm{~km}, 0.5 \mathrm{~km}, 1 \mathrm{~km}$ and $1.5 \mathrm{~km}$ for the roosting state were selected.

(2) Form the data sets for SDM

Points with instantaneous speed and travel distance more than $1 \mathrm{~km}$ within an hour were treated as dispersal points and excluded from the SDM. In addition, multiple records for the same bird recorded within $0.5 \mathrm{~km}$ were pruned to minimize spatial autocorrelation. Finally, 1076 foraging points and 490 roosting points, which were labelled Foraging $C$ and Roosting C, respectively, were retained for further SDM.

\subsection{Environmental Variable}

In the landscape ecology context, the term 'scale' generally has two meanings: one refers to the grain or spatial resolution, which represents the smallest/shortest unit of observation; the second refers to the extent, indicating the spatial size or temporal duration [22]. In this study, we restrict the meaning of 'scale' to extent, which was represented by the size of a 'window' around each focal site. Window sizes with radii of $0.1,0.5,1,1.5,3,5,8$ and $10 \mathrm{~km}$ were designed according to the foraging and roosting scales [7]. Landscape features within the window were quantified by landscape composition and configuration. Landscape composition considers the presence and quality of habitat features, while landscape configuration considers the explicit spatial arrangement of habitat elements [28]. Under 
this framework, environmental data were arranged into four groups (Table 1): landscape composition, landscape configuration, natural factors and human disturbance.

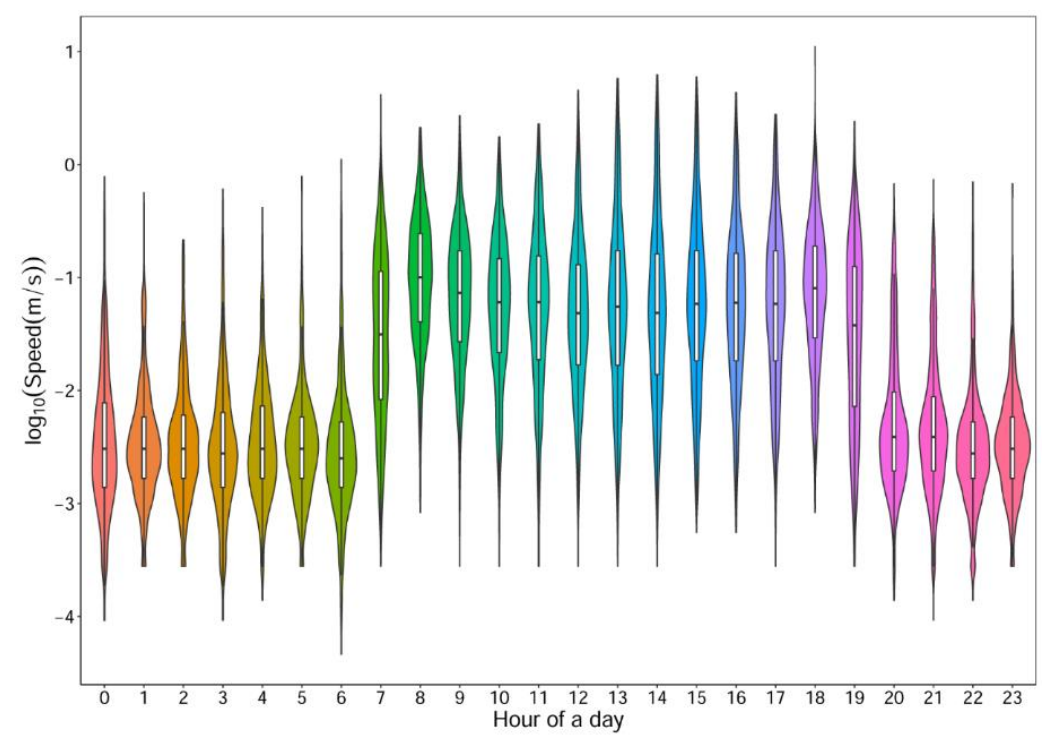

Figure 2. Hourly distribution of the travel distance over the course of a day.

Landscape composition and configuration were obtained from the land cover map. Landsat Operational Land Imager (OLI) images with a path-row number of 121-040, which were acquired on 23 January 2019, were selected to interpret the land cover map. OLI images generated on 31 July and 3 October 2018 were also selected to assist with the interpretation, as multitemporal features can help distinguish objects. Object-oriented segmentation was processed on these images through eCognition 9.3 (Trimble Inc.), during which geometry, position, texture and class-related features were generated. All these feature layers were sent into a random forest model to classify the land cover into ten classes: mudflat, lake, river, bare land, artificial surface, marsh, grassland, paddy field, forest and pond. To generate training and testing samples, a field investigation was conducted during December 2018, and 287 sampling plots and 781 unmanned aerial vehicle photos were generated. The overall classification accuracy, which was assessed based on verification samples from the field investigations and unmanned aerial vehicle photos, was over $92 \%$. Then, Fragstats 4.2 was used to calculate a number of landscape metrics quantifying landscape composition and configuration characteristics.

Landscape composition and configuration metrics reflected the spatial pattern characteristics, while natural factors were organized to address the process characteristics. Natural factors included two parts: topography and hydrology. Climate variables were omitted, as these data usually have a coarse resolution and are redundant with topographic variables at the local scale [36]. Topographic variables included elevation, aspect, slope and topographic roughness (i.e., local elevation variance), which were calculated with the Geomorphometry and Gradient Metrics Toolbox [37]. Hydrological variables included water seasonality and water occurrence. The water seasonality map describes the intra-annual behavior of water surfaces for a single year (2018 in this paper), while the water recurrence map provides information concerning the inter-annual behavior of water surfaces and captures the frequency with which water returns from year to year [38]. Human disturbance variables, described by density, distance and landscape metrics, were obtained through road and waterway layers from Open Street Map (https://www.openstreetmap.org/, accessed on 30 August 2021) and the land cover map. 
Table 1. Environmental variables considered for oriental white stork habitat selection analysis at the foraging and roosting scales. All layers except the distance variables were produced at 8 different spatial scales.

\begin{tabular}{|c|c|c|c|}
\hline Group & Variable & Abbreviation(unit) & $\begin{array}{l}\text { Description } \\
\end{array}$ \\
\hline Landscape Composition & $\begin{array}{l}\text { Percentage of focal Land } \\
\text { cover type }\end{array}$ & PLAND (\%) & $\begin{array}{l}\text { Percentage the landscape comprised of } \\
\text { the corresponding patch type. }\end{array}$ \\
\hline \multirow{10}{*}{$\begin{array}{l}\text { Landscape } \\
\text { Configuration }\end{array}$} & Mean path size & AM(ha) & Mean patch area of focal land cover type. \\
\hline & Largest patch index & LPI (\%) & $\begin{array}{l}\text { Percentage of total landscape area } \\
\text { comprised by the largest patch. }\end{array}$ \\
\hline & Edge density & $\mathrm{ED}(\mathrm{m} / \mathrm{ha})$ & Edge length on a per unit area basis. \\
\hline & Mean patch shape index & SHAPE_MN (-) & $\begin{array}{l}\text { Mean perimeter-area ratio of focal land } \\
\text { cover type. }\end{array}$ \\
\hline & Aggregation index & $\mathrm{AI}(\%)$ & $\begin{array}{c}\text { The number of like adjacencies involving } \\
\text { the corresponding class, divided by the } \\
\text { maximum possible number of like } \\
\text { adjacencies involving the corresponding } \\
\text { class. }\end{array}$ \\
\hline & $\begin{array}{l}\text { Interspersion and } \\
\text { juxtaposition index }\end{array}$ & IJI (\%) & $\begin{array}{l}\text { The observed interspersion over the } \\
\text { maximum possible interspersion for the } \\
\text { given number of patch types. }\end{array}$ \\
\hline & Patch cohesion index & COHESION (-) & $\begin{array}{l}\text { Physical connectedness of the } \\
\text { corresponding patch type. }\end{array}$ \\
\hline & Shannon's diversity index & SHDI (-) & Diversity in a landscape. \\
\hline & Patch density & PD (n/100 ha) & $\begin{array}{l}\text { The number of patches in the landscape, } \\
\text { divided by total landscape area. }\end{array}$ \\
\hline & $\begin{array}{c}\text { Distance to particular land } \\
\text { cover types }\end{array}$ & $\begin{array}{l}\text { Eucd_marsh, Eucd_mudflat, } \\
\text { Eucd_lake, etc. }(\mathrm{m})\end{array}$ & $\begin{array}{c}\text { Euclidean distance to mudflat, lake, river, } \\
\text { marsh, grassland, paddy field, forest or } \\
\text { pond. }\end{array}$ \\
\hline \multirow{3}{*}{ Natural features } & $\begin{array}{c}\text { Focal mean of Elevation, } \\
\text { Aspect, Slope and } \\
\text { Roughness }\end{array}$ & $\begin{array}{c}\text { Elevation }(\mathrm{m}) \text {, Aspect }\left(^{\circ}\right) \\
\text { Slope }\left(^{\circ}\right) \text { and Roughness }(-)\end{array}$ & $\begin{array}{c}\text { Derived from the DEM using Evans et al. } \\
2014 \text { ArcGIS Geomorphometric \& } \\
\text { Gradient Metrics Toolbox. }\end{array}$ \\
\hline & Water seasonality & Seasonality (-) & $\begin{array}{l}\text { Intra-annual behaviour of water surfaces } \\
\text { for a single year (2018). It is the number } \\
\text { of months water was present [38]. }\end{array}$ \\
\hline & Water recurrence & Recurrence (\%) & $\begin{array}{l}\text { The frequency with which water returns } \\
\text { from years to year expressed as a } \\
\text { percentage. It is a measurement of the } \\
\text { degree of inter-annual variability in the } \\
\text { presence of water [38]. }\end{array}$ \\
\hline \multirow{4}{*}{ Human disturbance } & Road density & Roaddensity $\left(\mathrm{m} / \mathrm{m}^{2}\right)$ & $\begin{array}{l}\text { Derived from road layer that is created } \\
\text { from Open Street Map. }\end{array}$ \\
\hline & Waterway density & Waterwaydensity (m/m2) & $\begin{array}{l}\text { Derived from waterway layer that is } \\
\text { created from Open Street Map. }\end{array}$ \\
\hline & $\begin{array}{l}\text { Distance to road, water } \\
\text { way and other artificial } \\
\text { surfaces }\end{array}$ & $\begin{array}{l}\text { Eucd_road, Eucd_waterway, } \\
\text { and Eucd_artificial (m) }\end{array}$ & $\begin{array}{l}\text { Euclidean distance to road, water way } \\
\text { and other artificial surfaces. }\end{array}$ \\
\hline & $\begin{array}{l}\text { Landscape composition } \\
\text { and configuration of } \\
\text { artificial surfaces }\end{array}$ & $\begin{array}{l}\text { PLAND_artificial, } \\
\text { AREA_MN_artificial, } \\
\text { AI_artificial, etc. }\end{array}$ & $\begin{array}{l}\text { Landscape metrics that describe the } \\
\text { characteristic of artificial surface. }\end{array}$ \\
\hline
\end{tabular}

\subsection{Univariate Model for Best Scale Selection and Variate Preselection}

As one of the most popular tools for species distribution and environmental niche modelling, the MaxEnt software package was selected to identify the environmental drivers for determining the storks' habitat suitability $[39,40]$. MaxEnt, which estimates the probability distribution of species occurrence based on constraints from environmental factors, is a robust technique that performs well against similar methods even with data limitations and biases [41-44].

To identify the scale that most influenced habitat selection, we used the MaxEnt model to predict relative habitat suitability at four scales for each pair of states based on each variable. For each focal variable, we ran univariate models at four scales (i.e., radii) for each two states. 
Each model was run in 50 replicates with 1000 maximum iterations, and at each run, 75\% of the records were randomly selected to train the model, while the remaining $25 \%$ were used as test records. The area under the curve (AUC) of the receiver operating characteristic (ROC) plot, the most frequently used method in SDM, was selected to evaluate the models. The scale at which a univariate model produced the highest AUC was retained to create a multivariate model with all variables at their best performing scale (Tables S1 and S2) [20].

Then, environmental variables with a test AUC $\leq 0.5$ were excluded from further analysis, while the remaining variables were checked for multicollinearity. Collinear variables (Pearson correlation of 0.6 or greater) were pruned by retaining those with higher test AUC scores $[19,20,45]$ and more ecological relevance [14]. This resulted in the inclusion of 17 out of the 90 initial variables for the foraging state and 20 for the roosting state (Figures S1 and S2).

\subsection{Multiscale Model for Habitat Selection}

All predictors and response variables were standardized using the Z-score to interpret parameter estimates on a comparable scale. Models with all combinations of the remaining scale-optimized variables were compared via the corrected Akaike's information criterion (AICc), and only those with $\triangle \mathrm{AICc}<2$ of the top ranked models were selected as final models (Tables S3 and S4). Then, model averaging was performed based on AICc weights when multiple models were selected [25]. These procedures were performed using the function dredge in the R package MuMIn. Variables contained in the averaged model were labelled as final multiscale-optimized variables. To evaluate the relative importance of these variables, we calculated the relative effect of the parameter estimates for each of the variables compared with that of all parameters [46]. The following four variance fractions were also examined: (1) landscape composition, (2) landscape configuration, (3) natural factors, and (4) human disturbance. This method is similar to variance partitioning analysis.

Then, to gain insights into how the probability of occurrence (habitat suitability) changes with environmental variables (habitat selection process), we ran a multiscale SDM using these scale-optimized variables contained in the averaged model [47]. Response curves, generated by the MaxEnt model that uses only one variable each time, were used to show how the occurrence depends on the corresponding variable.

\section{Results}

\subsection{Univariate Model}

Univariate scaling analysis was used to interpret the substantial sensitivity of the relationship between the storks' habitat suitability and the scale of analysis for all variables. The scale at which the highest AUC was obtained for the focal variate was identified as its optimized scale. For roosting habitat selection, almost all variates, except mudflats, achieved their highest AUC values at the scale of $1.5 \mathrm{~km}$, which was the largest scale selected in this study for roosting states. For mudflats, the configuration metrics describing aggregation in space (IJI, AI and COHESION) presented the highest AUC values at fine scales $(0.5 \mathrm{~km}$ or $1 \mathrm{~km})$, while the metrics describing landscape fragmentation (ED, LPI and SHAPE_MN) expressed the best performance at a larger scale $(1.5 \mathrm{~km})$. For foraging habitat selection, stork occurrence was mainly affected by metrics at a moderate scale $(5 \mathrm{~km})$, except for road density and waterway density of human disturbance, roughness of natural factors and aggregation of forest, which presented best performing models at a broader scale $(8 \mathrm{~km}$ or $10 \mathrm{~km})$. Further details of the optimal scale of each variable can be found in the Supplementary Materials (Tables S1 and S2).

\subsection{Multiscale Habitat Selection for Foraging}

The averaged model (based on all best models with $\triangle \mathrm{AICc}<2$, Table S3) that included all of the final multiscale-optimized variables explained up to $67.6 \%$ (adjusted $R^{2}$ ) of the total variation observed in foraging habitat selection (Figure 3a). Landscape metrics describing composition and configuration accounted for $71.5 \%$ of the explained variance, which was greater than that explained by human disturbance $(14.5 \%)$ and natural factors 
(14.0\%). The percentage of the landscape covered by paddy fields at the 5-km scale (PLAND_paddyfield_5km) alone accounted for $17.6 \%$ of the explained variance, albeit negatively. The percentage of total landscape area comprised the largest patch of lake at the 5-km scale (LPI_lake_5km) and surface roughness at the $8 \mathrm{~km}$ (roughness_8km) scale also had significant negative effects on habitat selection for foraging, while the distance to artificial surface (Eucd_artificial) was the most positive variable. Slope, water seasonality and distance to the waterway were never significant predictors of habitat selection for foraging. Storks prefer landscapes with paddy field cover lower than $5 \%$ and mudflat coverage of approximately $32 \%$ at the $5-\mathrm{km}$ scale. Storks prefer to forage near small lakes or large rivers (Figure 4). In addition, storks prefer to forage far from the artificial surfaces and where the surface roughness is not high at the $8-\mathrm{km}$ scale.

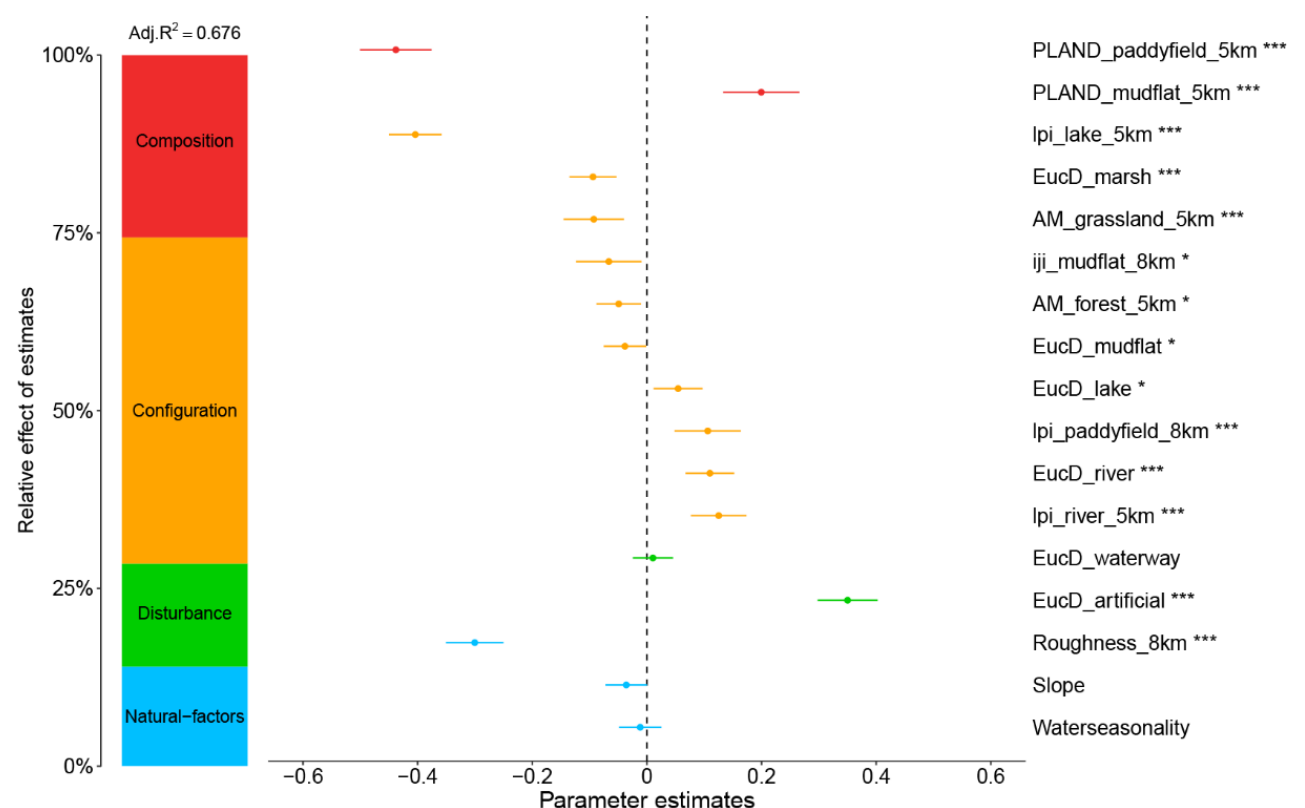

(a) Foraging

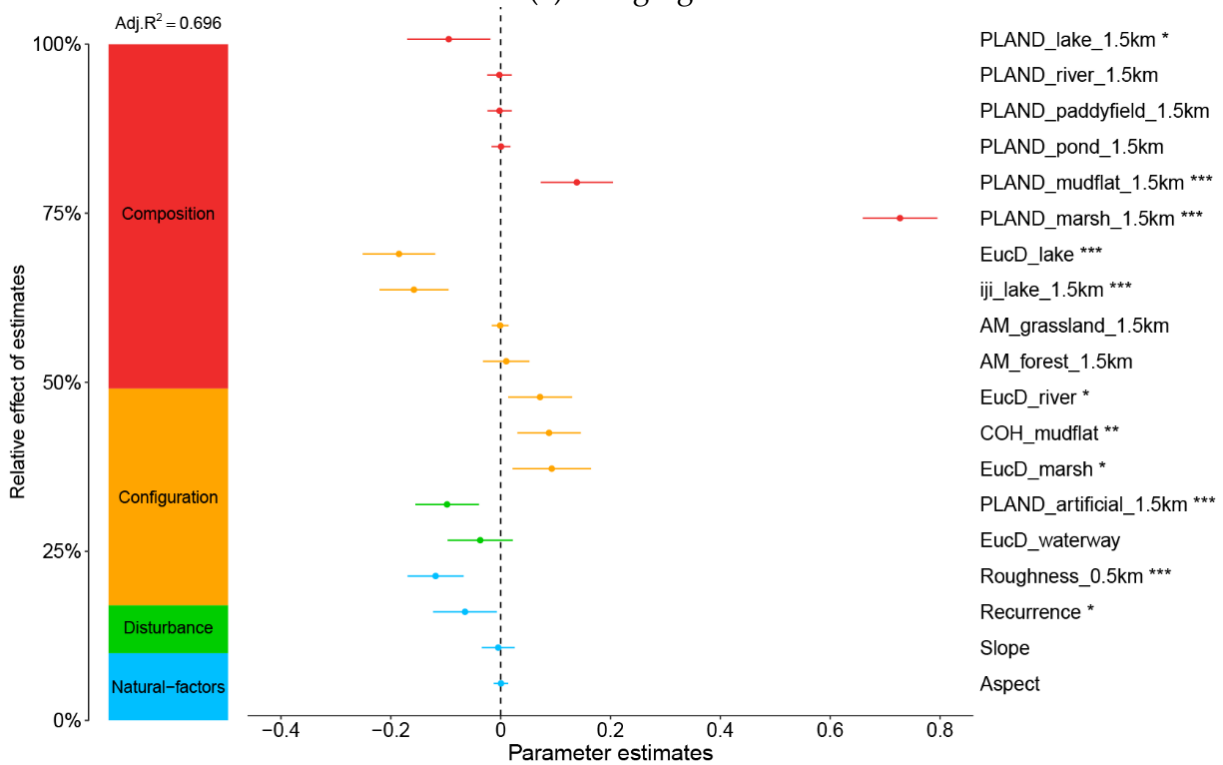

(b) Roosting

Figure 3. Effect of factors on habitat selection. (a) Foraging; (b) Roosting. Average parameter estimates (standardized regression coefficients) of model predictors, associated 95\% confidence intervals and relative importance of each factor, expressed as the percentage of explained variance. The adjusted (adj.) $R^{2}$ of the averaged model and the $p$ value of each predictor are given as ${ }^{*} p<0.05 ;{ }^{* *} p<0.01 ;{ }^{* *} p<0.001$. 

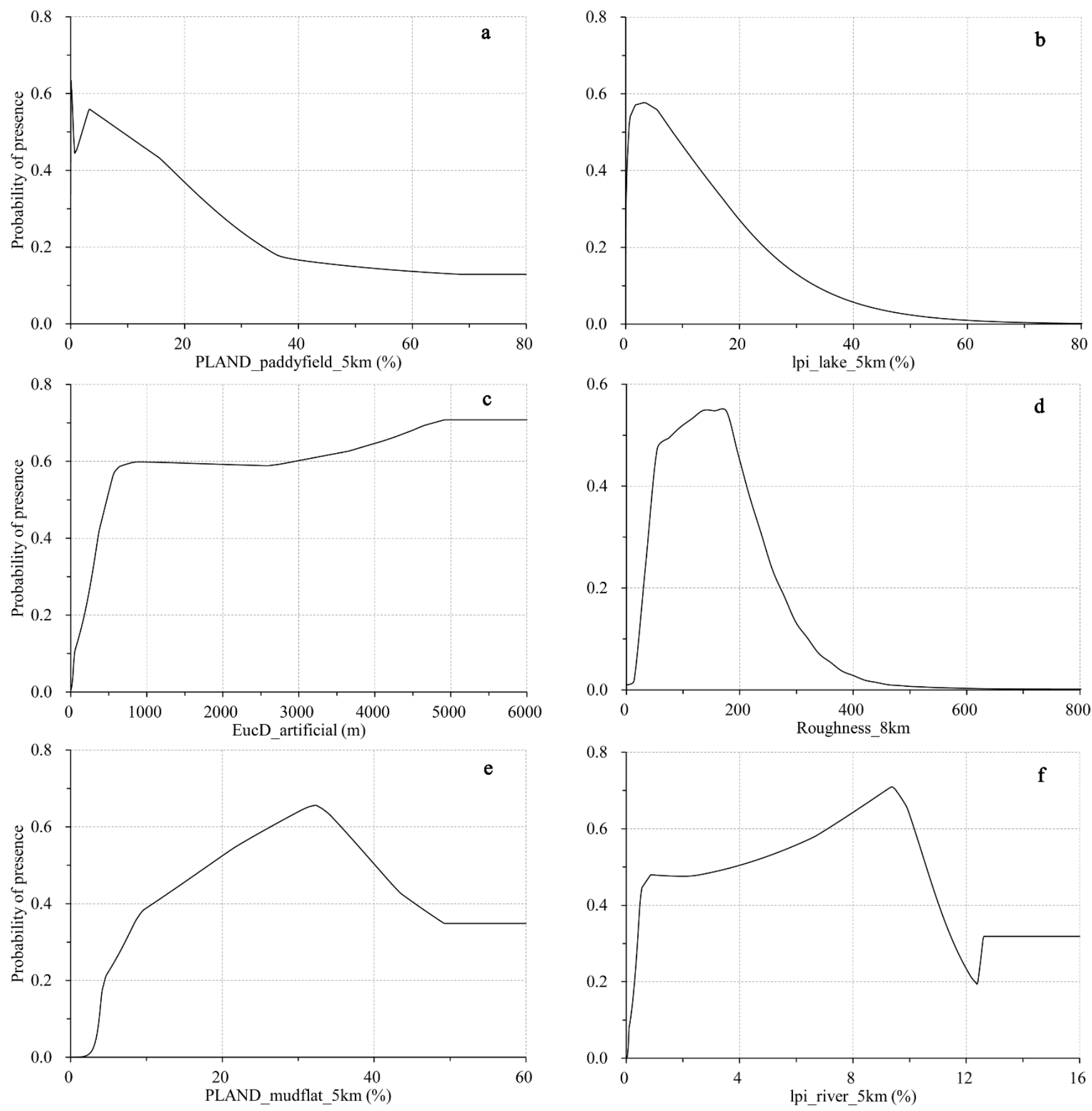

Figure 4. Response curves of top ranked variables for foraging: (a) PLAND of paddyfield at the 5-km scale, (b) LPI of lake at the $5-\mathrm{km}$ scale, (c) distance to artificial surfaces, (d) surface roughness at the 8-km scale, (e) PLAND of mudflat at the $5-\mathrm{km}$ scale and (f) LPI of river at the $5-\mathrm{km}$ scale.

\subsection{Multiscale Habitat Selection for Roosting}

Similarly, the averaged model, based on all best models with $\triangle$ AICc $<2$ (Table S4), showed high explanatory power ( $a d j . R^{2}=0.696$ ) for roosting habitat selection (Figure $3 \mathrm{~b}$ ). Landscape composition and configuration accounted for $83.0 \%$ of the explained variance. The percentage of the landscape covered by marsh at the 1.5-km scale (PLAND_marsh_1.5km) explained the most significant and positive effect $(38.4 \%)$ on habitat selection for roosting, while distance to the lake (Eucd_lake) was the most negative predictor $(9.8 \%)$. In contrast, the percentage of landscape covered by rivers, paddy fields and ponds at the $1.5-\mathrm{km}$ scale; the mean patch area of grassland and forest at the $1.5-\mathrm{km}$ scale; the distance to waterways; and the 
slope and aspect were never significant predictors of habitat selection for roosting. Storks prefer areas with $50 \%$ marsh or mudflat cover (Figure 5). Areas near the lake, which were not adjacent to other patch types, also tended to be used as roosting habitats. Similar to foraging habitat selection, storks prefer areas with low artificial surface proportions and surface roughness.
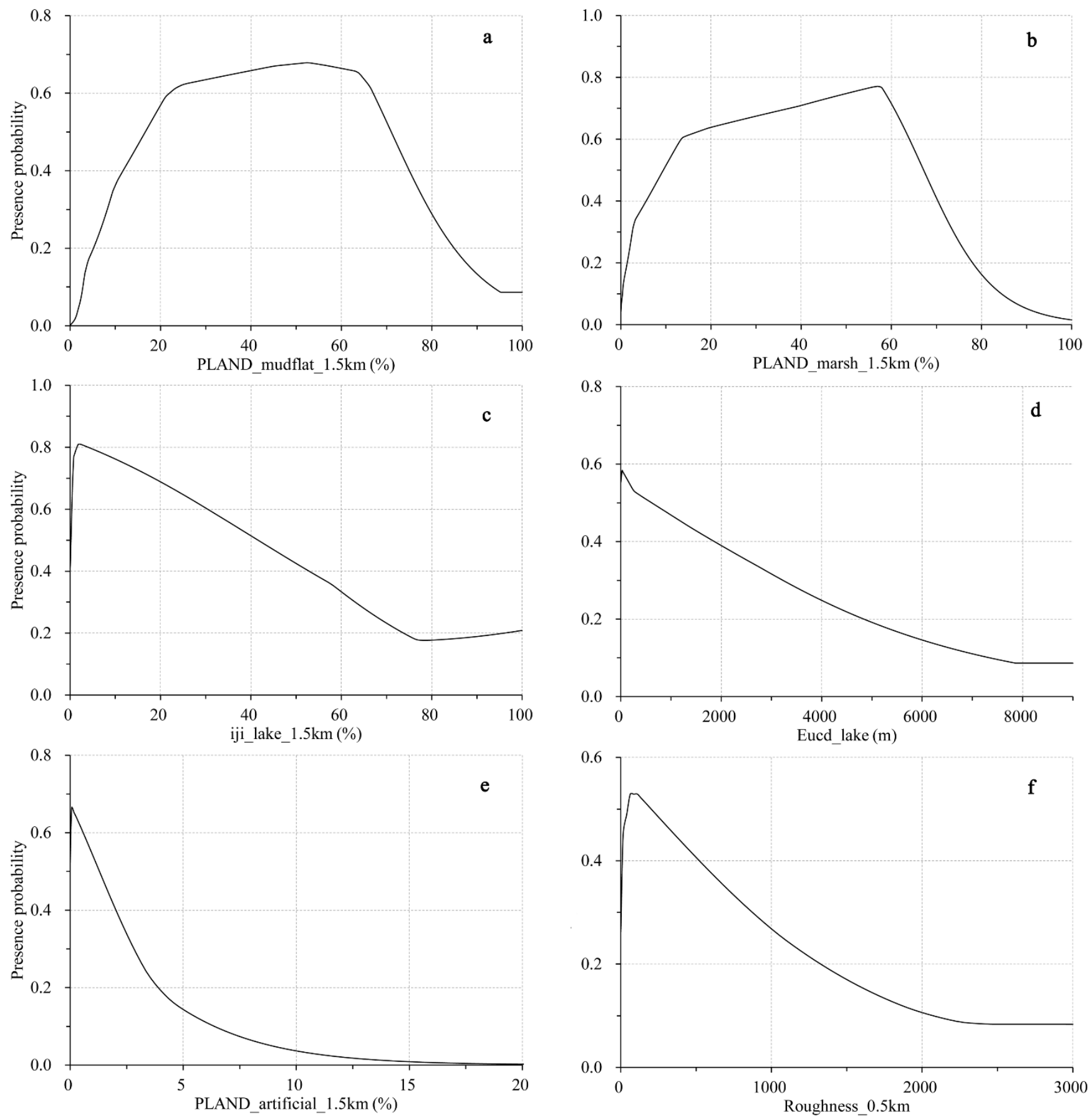

Figure 5. Response curves of top ranked variables for roosting. (a) PLAND of mudflat at the 1.5-km scale, (b) PLAND of marsh at the 1.5-km scale, (c) IJI of lake at the 1.5-km scale, (d) distance to lake, (e) PLAND of artificial surfaces at the 1.5-km scale and (f) surface roughness at the $0.5-\mathrm{km}$ scale. 


\section{Discussion}

\subsection{Landscape Features Are Necessary for Understanding Habitat Selection}

Clarifying the habitat selection characteristics of storks in terms of land cover types, landscape composition and landscape configuration is essential to developing a more complete and comprehensive understanding of habitat selection mechanisms and formulating more targeted recovery or protection strategies. In general, our findings are consistent with those of previous studies $[48,49]$, indicating that storks prefer areas covered by mudflats or marshes. However, these traditional studies usually focus habitat selection on land cover types, which we treated as habitat selection at the point scale (Figure 6), and previous studies tend to ignore the effects of landscape composition and configuration. In our study, we detailed habitat selection by using landscape metrics to describe landscape features. Our results indicate that landscape composition and configuration are determinant drivers affecting storks' habitat selection, both for foraging and roosting, highlighting the importance of landscape features. However, it is worth noting that landscape configuration was a more powerful predictor for foraging habitat selection, while roosting was more sensitive to landscape composition.

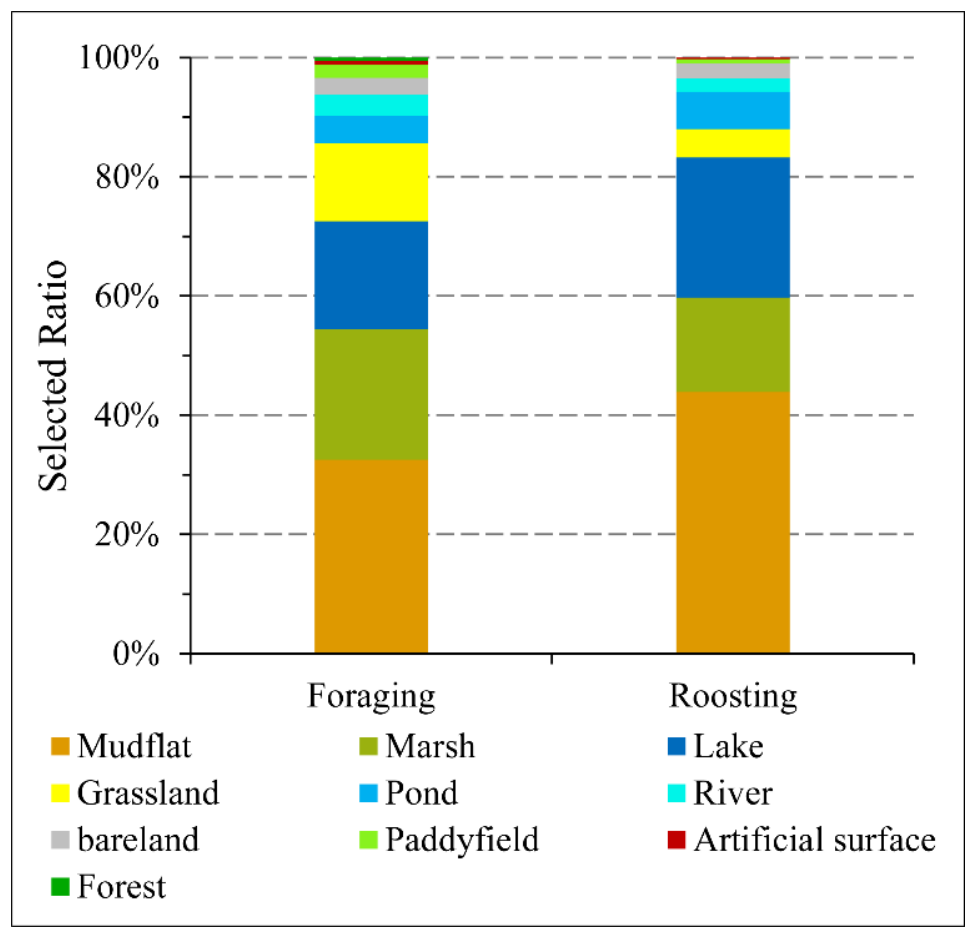

Figure 6. Habitat selection at the point scale.

Focusing on the top influential factors (greater than $10 \%$ explanation of the explained variance), we found that the four factors that had the greatest influence on the foraging of the storks fell into exactly four different categories, while the most influential factor affecting the habitat selection for roosting was the percentage of the landscape covered by marsh, i.e., a landscape composition variable (Figure 3). This variable alone explained $38.4 \%$ of the explained variance, which was higher than that explained by the combination of all variables belonging to the landscape configuration group. This result suggests that the factors affecting the foraging of storks are more extensive and complex, which may be related to the wide spatial distribution of food and the complexity of the environment in which the food is located. This result further suggests that only marshes or mudflats in the right locations are more likely to be selected, the correctness of which is highly dependent on landscape composition and configuration. 


\subsection{Satellite Tracking Technology Facilitates the Study of the Scale of Effect}

Combining enviro-anthropogenic variables measured at their best-performing scale in multivariate and multiscale models has been proven to be more accurate and realistic than traditional single-scale methods $[20,23,50]$. It is not surprising that the relative importance of variables usually changes with scale, as different processes may operate at different scales $[19,21-23]$. Therefore, variables need to be measured across several scales to identify the optimal scale that yields the strongest species-environment relationship, which is the so-called scale of effect [23].

In traditional studies involving the scale of effect, the optimal scale is usually identified by enumerating a series of scales $[19,23]$, which is steady but time-consuming. Miguet et al. (2016) proposed that the scale of effect should depend on species traits, especially those associated with individual mobility, such as dispersal distance and home range size. Taking advantage of the high spatial-temporal resolution satellite tracking data, we minimized the search range for the optimal scale by identifying the daily foraging and roosting scales. Then, the process of identifying the optimal scale of each variable was carried out around the calculated scale for foraging and roosting. Finally, multiscale and multistate habitat selection models were built with scale-optimized and collinearity-free variables. Although satellite tracking data collected from a limited number of waterbirds cannot represent general conditions at the population level, this approach may be the only currently available method to track fine-scale, large-extent and time-continuous movement [51], which facilitates the study of habitat selection and the scale of effect.

\subsection{Habitat Selection Research Should Be Detailed According to Habitat Requirements}

Simply unifying predictions by using all the occurrence data without distinguishing the differences among them may lead to misinterpretation, as species may rely on different resources across days, seasons, and behaviors [3]. In this study, the habitat requirements of Oriental White Storks during the wintering period at Poyang Lake were divided into two types: foraging and roosting, the characteristics of which were analyzed from the perspectives of landscape pattern and configuration, disturbance, and natural factors. Combined with the results of point-scale habitat selection that are commonly used in traditional studies, we find that storks prefer areas covered by mudflats, lakes or marshes for both foraging and roosting states (Figure 6). Moreover, the rate of habitat use declines as the distance to these areas increases (Figures 4 and 5). This result supports the central-place foraging hypothesis, which states that species often forage around their roosting sites during a period of the day to rest (Figure 7) [52]. Storks prefer roosting on mudflat, marsh or lake areas with a large proportion of marsh and mudflat areas positioned close to lakes with fewer other forms of land cover. Although they prefer to forage on the same land cover types with roosting, they prefer areas with fewer paddy fields, more mudflats, and close to scattered lakes. Furthermore, although the optimal scale for most of the influencing factors for foraging was $5 \mathrm{~km}$, the scale for topography was larger, at a scale of $8 \mathrm{~km}$. This result suggests that storks tend to perceive terrain on a large scale when foraging, which may be due to the influence of terrain on the dispersal ability or the spatial distribution and allocation of food. However, the opposite was true for roosting. The fine-scale sensitivity to topography probably reflects a tendency of storks to associate topography and cover. 

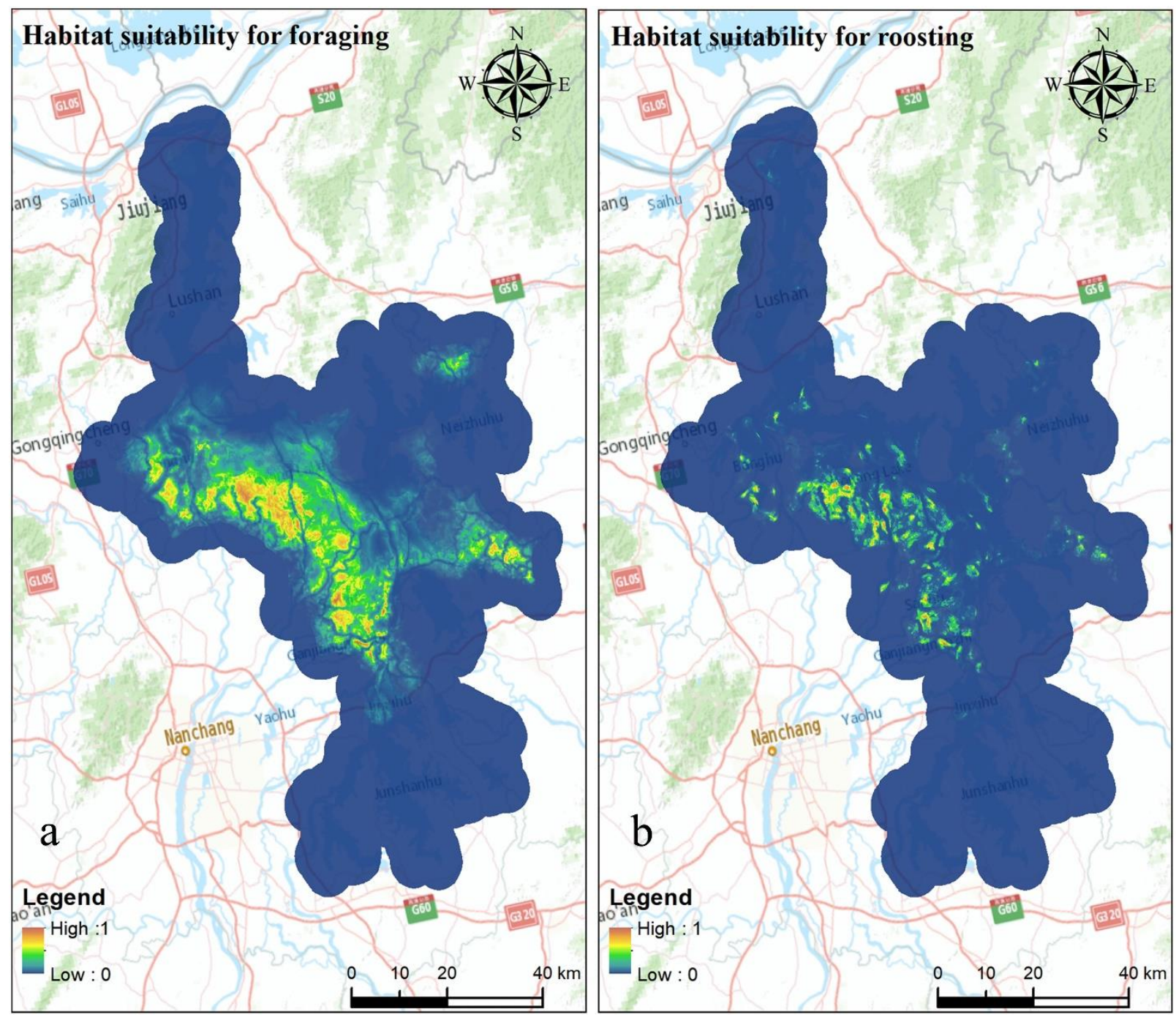

Figure 7. Habitat suitability map generated by scale-optimized variables: (a) habitat suitability for foraging and (b) habitat suitability for roosting.

\section{Conclusions}

The application of satellite tracking and remote sensing technology makes it possible to record detailed information on the characteristics of occurrence sites and their surrounding environments, thus facilitating the study of species-habitat relationships. Applying univariate and multiscale models, the optimized scale of each variable and its relative importance for different habitat requirements were identified in this paper. Our results confirm that storks' habitat selection varied with spatial scale and that these scaling relationships were not consistent among different habitat requirements (foraging or roosting) and environmental features. Landscape configuration was found to be a more powerful predictor for storks' foraging habitat selection, while roosting was more sensitive to landscape composition. The percentage of landscape covered by marsh and mudflat at the $1.5-\mathrm{km}$ scale mainly determines the suitability of a site as a roosting area, while factors affecting the foraging of storks are more extensive and complex. Given these differences in responses to habitat requirements, scale and landscape structure, a multiscale and multistate approach should be a mandatory process in conservation planning. 
Supplementary Materials: The following are available online at https: / www.mdpi.com/article/ 10.3390/rs13214397/s1, Figure S1: Correlation matrix of retained variables for final multi-scale habitat modeling of roosting state, Figure S2: Correlation matrix of retained variables for final multi-scale habitat modeling of foraging state, Table S1: AUC for optimized scale selection of the variables for foraging state, Table S2: AUC for optimized scale selection of the variables for roosting, Table S3: Component models with $\triangle \mathrm{AICc}<2$ of the top ranked models for foraging, Table S4: Component models with $\triangle \mathrm{AICc}<2$ of the top ranked models for roosting.

Author Contributions: Conceptualization, J.L.; methodology, J.L. and L.Z.; validation, J.L. and L.Z.; investigation, J.L., Y.Z., W.D. and F.Q.; writing—original draft preparation, J.L.; writing-review and editing, J.L., F.Q. and K.M.; visualization, J.L.; project administration, K.M.; funding acquisition, K.M. All authors have read and agreed to the published version of the manuscript.

Funding: This research was funded by the National Key R\&D Program of China (Grant No. 2017YFC0505804) and the National Natural Science Foundation of China (NSFC 41601439, 31900191)

Data Availability Statement: Not applicable.

Acknowledgments: We would like to thank the Poyang Lake National Nature Reserve and the Nanji Wetland National Nature Reserve for assisting with field investigation. We are grateful to Shuang Zhang, Zhangqi Ding and Ming Yan for their help with statistical analysis and visualization. We are also indebted to the editor and anonymous reviewers for insightful comments on this paper.

Conflicts of Interest: The authors have no conflict of interest to declare.

\section{References}

1. Dzialak, M.R.; Olson, C.V.; Webb, S.L.; Harju, S.M.; Winstead, J.B. Incorporating within- and between-patch resource selection in identification of critical habitat for brood-rearing greater sage-grouse. Ecol. Process. 2015, 4, 5. [CrossRef]

2. Wang, Z.; Li, N.; Gao, S.; An, S. Response of wintering waterbird diversity to reclamation history and post-reclamation habitat along Yellow Sea coast. Integr. Zool. 2020, 15, 595-602. [CrossRef] [PubMed]

3. Frans, V.F.; Augé, A.A.; Edelhoff, H.; Erasmi, S.; Balkenhol, N.; Engler, J.O. Quantifying apart what belongs together: A multi-state species distribution modelling framework for species using distinct habitats. Methods Ecol. Evol. 2018, 9, 98-108. [CrossRef]

4. Amirkhiz, R.G.; Dixon, M.D.; Palmer, J.S.; Swanson, D.L. Investigating niches and distribution of a rare species in a hierarchical framework: Virginia's Warbler (Leiothlypis virginiae) at its northeastern range limit. Landsc. Ecol. 2021, 36, 1039-1054. [CrossRef]

5. Duan, R.; Kong, X.; Huang, M.; Wu, G.; Wang, Z. SDM vs pecies: A software for creating virtual species for species distribution modelling. Ecography 2015, 38, 108-110. [CrossRef]

6. Engler, J.O.; Stiels, D.; Schidelko, K.; Strubbe, D.; Quillfeldt, P.; Brambilla, M. Avian SDMs: Current state, challenges, and opportunities. J. Avian Biol. 2017, 48, 1483-1504. [CrossRef]

7. Miguet, P.; Jackson, H.B.; Jackson, N.D.; Martin, A.E.; Fahrig, L. What determines the spatial extent of landscape effects on species? Landsc. Ecol. 2016, 31, 1177-1194. [CrossRef]

8. Anderson, R.P.; Martínez-Meyer, E. Modeling species' geographic distributions for preliminary conservation assessments: An implementation with the spiny pocket mice (Heteromys) of Ecuador. Biol. Conserv. 2004, 116, 167-179. [CrossRef]

9. Graham, C.H.; Elith, J.; Hijmans, R.J.; Guisan, A.; Peterson, A.T.; Loiselle, B.A. The influence of spatial errors in species occurrence data used in distribution models. J. Appl. Ecol. 2007, 45, 239-247. [CrossRef]

10. Gschweng, M.; Kalko, E.K.V.; Berthold, P.; Fiedler, W.; Fahr, J. Multi-temporal distribution modelling with satellite tracking data: Predicting responses of a long-distance migrant to changing environmental conditions. J. Appl. Ecol. 2012, 49, 803-813. [CrossRef]

11. Li, X.; Si, Y.; Ji, L.; Gong, P. Dynamic response of East Asian Greater White-fronted Geese to changes of environment during migration: Use of multi-temporal species distribution model. Ecol. Model. 2017, 360, 70-79. [CrossRef]

12. Blakey, R.V.; Siegel, R.B.; Webb, L.; Dillingham, C.P.; Johnson, M.; Kesler, D.C. Multi-scale habitat selection by Northern Goshawks (Accipiter gentilis) in a fire-prone forest. Biol. Conserv. 2020, 241, 108348. [CrossRef]

13. Brambilla, M.; Saporetti, F. Modelling distribution of habitats required for different uses by the same species: Implications for conservation at the regional scale. Biol. Conserv. 2014, 174, 39-46. [CrossRef]

14. Zhang, W.; Li, X.; Yu, L.; Si, Y. Multi-scale habitat selection by two declining East Asian waterfowl species at their core spring stopover area. Ecol. Indic. 2018, 87, 127-135. [CrossRef]

15. Zuckerberg, B.; Fink, D.; La Sorte, F.A.; Hochachka, W.M.; Kelling, S. Novel seasonal land cover associations for eastern North American forest birds identified through dynamic species distribution modelling. Divers. Distrib. 2016, 22, 717-730. [CrossRef]

16. Taboada, A.; von Wehrden, H.; Assmann, T.; Srygley, R.B. Integrating life stages into ecological niche models: A case study on tiger beetles. PLoS ONE 2013, 8, e70038. [CrossRef]

17. Ashrafzadeh, M.R.; Khosravi, R.; Adibi, M.A.; Taktehrani, A.; Wan, H.Y.; Cushman, S.A. A multi-scale, multi-species approach for assessing effectiveness of habitat and connectivity conservation for endangered felids. Biol. Conserv. 2020, 245, 108523. [CrossRef] 
18. Wevers, J.; Beenaerts, N.; Casaer, J.; Zimmermann, F.; Artois, T.; Fattebert, J. Modelling species distribution from camera trap by-catch using a scale-optimized occupancy approach. Remote Sens. Ecol. Conserv. 2021, 7, 534-549. [CrossRef]

19. Bellamy, C.; Scott, C.; Altringham, J. Multiscale, presence-only habitat suitability models: Fine-resolution maps for eight bat species. J. Appl. Ecol. 2013, 50, 892-901. [CrossRef]

20. Sánchez, M.C.M.; Cushman, S.A.; Saura, S. Scale dependence in habitat selection: The case of the endangered brown bear (Ursus arctos) in the Cantabrian Range (NW Spain). Int. J. Geogr. Inf. Sci. 2013, 28, 1531-1546. [CrossRef]

21. Jackson, H.B.; Fahrig, L. Are ecologists conducting research at the optimal scale? Glob. Ecol. Biogeogr. 2015, 24, 52-63. [CrossRef]

22. McGarigal, K.; Wan, H.Y.; Zeller, K.A.; Timm, B.C.; Cushman, S.A. Multi-scale habitat selection modeling: A review and outlook. Landsc. Ecol. 2016, 31, 1161-1175. [CrossRef]

23. Martínez-Ruiz, M.; Arroyo-Rodríguez, V.; Franch-Pardo, I.; Renton, K. Patterns and drivers of the scale of effect of landscape structure on diurnal raptors in a fragmented tropical dry forest. Landsc. Ecol. 2020, 35, 1309-1322. [CrossRef]

24. Wu, J. Effects of changing scale on landscape pattern analysis: Scaling relations. Landsc. Ecol. 2004, 19, 125-138. [CrossRef]

25. Carrara, E.; Arroyo-Rodríguez, V.; Rivera, J.H.V.; Schondube, J.E.; de Freitas, S.M.; Fahrig, L. Impact of landscape composition and configuration on forest specialist and generalist bird species in the fragmented Lacandona rainforest, Mexico. Biol. Conserv. 2015, 184, 117-126. [CrossRef]

26. Quesnelle, P.E.; Fahrig, L.; Lindsay, K. Effects of habitat loss, habitat configuration and matrix composition on declining wetland species. Biol. Conserv. 2013, 160, 200-208. [CrossRef]

27. Mukherjee, T.; Sharma, V.; Sharma, L.K.; Thakur, M.; Joshi, B.D.; Sharief, A.; Thapa, A.; Dutta, R.; Dolker, S.; Tripathy, B.; et al. Landscape-level habitat management plan through geometric reserve design for critically endangered Hangul (Cervus hanglu hanglu). Sci. Total Environ. 2021, 777, 146031. [CrossRef] [PubMed]

28. Thompson, C.M.; McGarigal, K. The influence of research scale on bald eagle habitat selection along the lower Hudson River, New York (USA). Landsc. Ecol. 2002, 17, 569-586. [CrossRef]

29. Baldan, D.; Piniewski, M.; Funk, A.; Gumpinger, C.; Flödl, P.; Höfer, S.; Hauer, C.; Hein, T. A multi-scale, integrative modeling framework for setting conservation priorities at the catchment scale for the Freshwater Pearl Mussel Margaritifera margaritifera. Sci. Total Environ. 2020, 718, 137369. [CrossRef] [PubMed]

30. IUCN. Ciconia Boyciana. BirdLife International: The IUCN Red List of Threatened Species 2018. 2018. Available online: https: / / www.iucnredlist.org/ (accessed on 30 August 2021).

31. Li, Y.; Zhang, Q.; Cai, Y.; Tan, Z.; Wu, H.; Liu, X.; Yao, J. Hydrodynamic investigation of surface hydrological connectivity and its effects on the water quality of seasonal lakes: Insights from a complex floodplain setting (Poyang Lake, China). Sci. Total Environ. 2019, 660, 245-259. [CrossRef] [PubMed]

32. Zhu, Z.; Huai, W.; Yang, Z.; Li, D.; Wang, Y. Assessing habitat suitability and habitat fragmentation for endangered Siberian cranes in Poyang Lake region, China. Ecol. Indic. 2021, 125, 107594. [CrossRef]

33. Li, Y.; Qian, F.; Silbernagel, J.; Larson, H. Community structure, abundance variation and population trends of waterbirds in relation to water level fluctuation in Poyang Lake. J. Great Lakes Res. 2019, 45, 976-985. [CrossRef]

34. Si, Y.; Xu, Y.; Xu, F.; Li, X.; Zhang, W.; Wielstra, B.; Wei, J.; Liu, G.; Luo, H.; Takekawa, J.; et al. Spring migration patterns, habitat use, and stopover site protection status for two declining waterfowl species wintering in China as revealed by satellite tracking. Ecol. Evol. 2018, 8, 6280-6289. [CrossRef]

35. Kennerley, R.; Nicoll, M.; Butler, S.; Young, R.; Nuñez-Miño, J.; Brocca, J.; Turvey, S. Home range and habitat data for Hispaniolan mammals challenge assumptions for conservation management. Glob. Ecol. Conserv. 2019, 18, 640. [CrossRef]

36. Wilson, J.; Sexton, J.O.; Jobe, R.T.; Haddad, N.M. The relative contribution of terrain, land cover, and vegetation structure indices to species distribution models. Biol. Conserv. 2013, 164, 170-176. [CrossRef]

37. Evans, J.S.; Oakleaf, J.; Cushman, S.A.; Theobald, D. An ArcGIS Toolbox for Surface Gradient and Geomorphometric Modeling, Version 2.0-0; The Nature Conservancy and University of Wyoming: Laramie, WY, USA, 2014; Available online: http:/ / evansmurphy. wix.com/evansspatial (accessed on 30 August 2021).

38. Pekel, J.-F.; Cottam, A.; Gorelick, N.; Belward, A.S. High-resolution mapping of global surface water and its long-term changes. Nature 2016, 540, 418-422. [CrossRef] [PubMed]

39. Merow, C.; Smith, M.J.; Silander, J.A. A practical guide to MaxEnt for modeling species' distributions: What it does, and why inputs and settings matter. Ecography 2013, 36, 1058-1069. [CrossRef]

40. Phillips, S.J.; Anderson, R.P.; Schapire, R.E. Maximum entropy modeling of species geographic distributions. Ecol. Model. 2006, 190, 231-259. [CrossRef]

41. Elith, J.; Graham, C.H.; Anderson, R.P.; Dudík, M.; Ferrier, S.; Guisan, A.; Hijmans, R.J.; Huettmann, F.; Leathwick, J.R.; Lehmann, A.; et al. Novel methods improve prediction of species' distributions from occurrence data. Ecography 2006, 29, 129-151. [CrossRef]

42. Elith, J.; Phillips, S.J.; Hastie, T.; Dudík, M.; Chee, Y.E.; Yates, C.J. A statistical explanation of MaxEnt for ecologists. Divers. Distrib. 2011, 17, 43-57. [CrossRef]

43. Hill, N.J.; Tobin, A.J.; Reside, A.E.; Pepperell, J.G.; Bridge, T.C.L. Dynamic habitat suitability modelling reveals rapid poleward distribution shift in a mobile apex predator. Glob. Chang. Biol. 2016, 22, 1086-1096. [CrossRef]

44. Phillips, S.J.; Anderson, R.P.; Dudík, M.; Schapire, R.E.; Blair, M.E. Opening the black box: An open-source release of Maxent. Ecography 2017, 40, 887-893. [CrossRef] 
45. Clemente, P.; Calvache, M.; Antunes, P.; Santos, R.; Cerdeira, J.O.; Martins, M.J. Combining social media photographs and species distribution models to map cultural ecosystem services: The case of a Natural Park in Portugal. Ecol. Indic. 2019, 96, 59-68. [CrossRef]

46. Gross, N.; Le Bagousse-Pinguet, Y.; Liancourt, P.; Berdugo, M.; Gotelli, N.J.; Maestre, F.T. Functional trait diversity maximizes ecosystem multifunctionality. Nat. Ecol. Evol. 2017, 1, 0132. [CrossRef] [PubMed]

47. Wang, G.; Wang, C.; Guo, Z.; Dai, L.; Wu, Y.; Liu, H.; Li, Y.; Chen, H.; Zhang, Y.; Zhao, Y.; et al. A multiscale approach to identifying spatiotemporal pattern of habitat selection for red-crowned cranes. Sci. Total Environ. 2020, 739, 139980. [CrossRef] [PubMed]

48. Wang, Y.; Ruan, L.; Huang, P.; Luo, H.; Chen, S. Habitat Selection and Protection of Ciconia boyciana during Overwintering Stage in Poyang Lake. J. Anhui Agric. Sci. 2010, 38, 7376-7378.

49. Xie, P. Habitat Comparison of Oriental White Stork (Ciconia Boyciana) in Different Periods. Master's Thesis, Northeast Forestry University, Harbin, China, 2018.

50. Tehrani, N.A.; Naimi, B.; Jaboyedoff, M. Toward community predictions: Multi-scale modelling of mountain breeding birds' habitat suitability, landscape preferences, and environmental drivers. Ecol. Evol. 2020, 10, 5544-5557. [CrossRef]

51. Hebblewhite, M.; Haydon, D. Distinguishing technology from biology: A critical review of the use of GPS telemetry data in ecology. Philos. Trans. R. Soc. B Biol. Sci. 2010, 365, 2303-2312. [CrossRef]

52. Orians, G.H.; Pearson, N.E. On the Theory of Central Place Foraging. In Analysis of Ecological Systems; Ohio State University Press: Columbus, OH, USA, 1979; pp. 155-177. 